Article

\title{
Effect of Bacterial Strains Isolated from Stored Shiitake (Lentinula edodes) on Mushroom Biodeterioration and Mycelial Growth
}

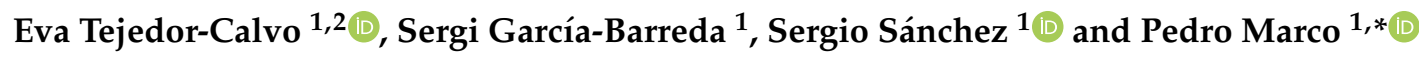 \\ 1 Forest Resources Unit, Agrifood Research and Technology Centre of Aragon (CITA), Agrifood Institute of \\ Aragón-IA2 (CITA-Zaragoza University), Av. de Montañana, 930, 50059 Zaragoza, Spain; \\ etejedorc@aragon.es (E.T.-C.); sgarciaba@cita-aragon.es (S.G.-B.); ssanchezd@aragon.es (S.S.) \\ 2 Department of Production and Characterization of Novel Foods, Institute of Food Science \\ Research-CIAL (UAM-CSIC), C/Nicolas Cabrera 9, Campus de Cantoblanco, Universidad Autónoma de \\ Madrid, 28049 Madrid, Spain \\ * Correspondence: pmarcomo@cita-aragon.es
}

Received: 3 June 2020; Accepted: 22 June 2020; Published: 24 June 2020

check for updates

\begin{abstract}
Shiitake (Lentinula edodes) is a fungus that attracts the attention of consumers and researchers due to its flavour and bioactive compounds with biological activities. However, it swiftly loses quality because of its short shelf life. The present work evaluated the shelf life of cultivated shiitake carpophores with a weekly monitoring of the physico-chemical, microbiological, and sensory parameters under three different storage conditions. To establish the mycopathogenicity of fruitbody-inhabiting bacterial microbiota, 48 strains were isolated from shiitake throughout its storage time and subsequently inoculated on cap cuticles and slices. Additionally, an antibiogram of these bacterial strains against shiitake mycelium was performed. Shiitake had a total microbial load of $5 \log \mathrm{cfu} / \mathrm{g}$, composed mainly of Pseudomonas genus, followed by Enterobacteriaceae family, and moulds and yeasts. Among the 48 bacterial strains identified, 18 belonged to the Enterobacteriaceae family and 21 to the Pseudomonas genus. The biodeterioration capacity of the isolated strains increased throughout the conservation period, with slices being more damaged than cap cuticles. We observed a mycopathogenic behaviour of Burkholderia sp., Ewingella americana, Serratia sp., Microbacterium sp. and Rahnella sp. strains, although only the latter highly inhibited shiitake vegetative mycelium growth.
\end{abstract}

Keywords: shiitake; shelf life; modified atmosphere; antibiogram; mycopathogen; bacteria; Rahnella

\section{Introduction}

Shiitake (Lentinula edodes (Berk.) Pegler) mushrooms are currently attracting the attention of consumers for their high nutrient value, gastronomic interest, and human health properties [1]. In the last decade, shiitake cultivation has increased exponentially, achieving the second position in the global mushroom industry after Agaricus bisporus (J.E. Lange) Imbach. Mushrooms have a short shelf life due to factors such as their high respiration and metabolic rates, rapid weight loss, and high microbiological load, which all together induce quality losses shortly after harvesting [2]. The distribution chain of this fresh product is highly conditioned by its short shelf life. In order to guarantee its sanitary aptitude, a combination of decontamination and preserving technologies-such as irradiation combined with modified atmosphere packaging - has been developed [3]. The use of ionisation technologies combined with refrigerated storage has also been reported to extend the shelf life of different mushrooms, including shiitake [2]. The modified atmosphere limits gas exchanges with the outside air, thus altering the atmosphere composition inside the package and decreasing the 
respiration rate of the product. Optimum conditions inside the package can be passively achieved as a result of mushroom respiration [4].

Bacteria, moulds, enzymatic activity and biochemical changes can cause physical spoilage of mushrooms during storage. The Pseudomonas genus is a very competitive microbial group in the rhizosphere which takes part symbiotically in the mushroom fruiting body development [5]. However, some species of this bacterial genus also appear to be responsible for mushroom postharvest deterioration, such as Pseudomonas tolaasii Paine, which is accountable for the surface browning produced by the action of the toolasin exotoxin. Yeasts such as Candida sake Uden and H.R. Buckley are also able to provoke post-harvest damages [6]. Ewingella americana Grimont et al. (Entobacteriaceae family) is associated with a browning disorder of the A. bisporus stipe, called internal stipe necrosis, which can also occur in other mushroom species [7]. Burkholderia gladioli pv. agaricicola Yabuuchi is an important pathogen in the mushroom industry, causing soft rotting symptoms over several important commercial mushrooms such as L. edodes, Pleurotus ostreatus (Jacq.) P. Kumm., Flammulina velutipes (Curtis) Singer, Pholiota nameko (T. Itô) S. Ito and S. Imai or Hypsizygus marmoreus (Peck) H.E. Bigelow [8].

In this work, several physico-chemical, microbiological and sensory parameters of shiitake mushrooms were monitored under three storage conditions until carpophores were completely degraded. Throughout the conservation period, different bacterial strains were isolated, selected and identified from all batches to detect possible changes in the predominant microbiota. These strains were subsequently inoculated on the cuticle, slices and mycelium of L. edodes mushroom caps, in order to identify which ones were primarily responsible for bacterial biodeterioration.

\section{Materials and Methods}

\subsection{Samples and Storage Conditions}

Shiitake mushrooms were purchased in Mercazaragoza food market (Zaragoza, Spain). Samples were transported to the laboratory and stored at $4{ }^{\circ} \mathrm{C}$ and $95 \%$ of relative humidity. For the experiment, mushrooms were stored under three conditions: (1) room temperature $\left(22^{\circ} \mathrm{C}\right)$ as a control $(\mathrm{C})$, (2) refrigerated at $4{ }^{\circ} \mathrm{C}(\mathrm{R})$, and (3) packaged in passive modified atmosphere under refrigeration at $4{ }^{\circ} \mathrm{C}$ (MAP). For all batches, semi-rigid polypropylene trays (TS250, Linpac) of $250 \mathrm{~mL}$ of capacity were used for packaging 6-7 mushrooms per tray (100 g approximately). $C$ and $R$ trays were wrapped with absorbent paper to retain moisture excess. The trays of the MAP treatment were heat-sealed using a manual packaging machine BOV 160 (ORA Constructeur, Trévoux, France) with a microperforated film composed of a double layer of polyethylene $(40 \mu \mathrm{m})$ and polyester $(12 \mu \mathrm{m})$, and having two microperforations $(50 \times 90 \mu \mathrm{m})$ per tray (PPLUS, Amcor Flexible, Madrid, Spain). A total of 15 trays per batch were prepared, so that three trays could be analysed in each sampling day.

\subsection{Shelf-Life Assay}

\subsubsection{Modified Atmosphere Gas Measurement}

The modification of the atmosphere composition inside heat-sealed trays was monitored using a respirometer CheckMate II (PBI Danasensor, Barcelona, Spain). $\mathrm{O}_{2}$ and $\mathrm{CO}_{2}$ concentrations were measured in each tray immediately after packaging, 24 and $48 \mathrm{~h}$ later, and then every seven days. The value presented for each sampling day is an average of three different trays.

\subsubsection{Determination of Weight Loss}

The weight of all the trays was measured immediately after packaging, and after that every seven days, with a Sartorius 3716 scale (Sartorius, Göttingen, Germany). The value presented for each batch on each sampling day is an average of three different trays. Weight loss is expressed as a percentage of the initial weight. 


\subsubsection{Microbial Analysis}

Microbial analyses included the quantification of aerobic mesophilic microorganisms (AMM; which constitute the total aerobic microbial load), Pseudomonas genus, Enterobacteriaceae family, lactic acid bacteria (LAB), and moulds and yeasts. The quantifications were done following the corresponding ISO Norm, with slight modifications as indicated in Rivera et al. [6]. The batches were analysed once a week until shiitake was completely degraded. Each sample $(25 \mathrm{~g})$ was serially diluted in sterile distilled peptone water $0.1 \%$ (Merck, Darmstadt, Germany), and homogenised using a laboratory blender Stomacher 400 Circulator (Seward Laboratory, London, England) during $2 \mathrm{~min}$ at $250 \mathrm{rpm}$ according to ISO Norm 6887-1:2017. In order to facilitate the subsequent selection and picking of the microbial colonies on the basis of colony morphology, quantifications were carried out in PCA agar plates by spread plating of $0.1 \mathrm{~mL}$. Culture media and incubation conditions for each microbial group were: (1) AMM: plate Count Agar (PCA) (Merck) during $72 \mathrm{~h}$ at $30 \pm 1{ }^{\circ} \mathrm{C}$; (2) Pseudomonas genus: Pseudomonas agar base (Oxoid, Basingstoke, Hampshire, U.K.) supplemented with cephaloridine-fucidin-cetrimide (CFC) during $48 \mathrm{~h}$ at $25 \pm 1{ }^{\circ} \mathrm{C}$; (3) Enterobacteriaceae family: violet red bile glucose (VRBG) (Oxoid) during $24 \mathrm{~h}$ at $30 \pm 1{ }^{\circ} \mathrm{C}$; (4) LAB: Man, Rogosa and Sharpe agar (MRS) (Merck) during $72 \mathrm{~h}$ at $30 \pm 1{ }^{\circ} \mathrm{C}$ (Oxoid), using anaerobic jars with an atmosphere generation system; and (5) moulds and yeasts: dichloran rose-bengal chloramphenicol agar (DRBC) (Merck), supplemented with $0.1 \%$ gentamicin (Carlier, Barcelona, Spain) to avoid Pseudomonas spp. growth, during 4 days at $25 \pm 1^{\circ} \mathrm{C}$. The value presented for the microbial count of each sampling day is the average of three measurements (one per tray, three trays per sampling day and batch), expressed as log cfu/g.

\subsubsection{Sensory Analysis}

A panel of eight trained tasters evaluated the quality and characteristics of shiitake mushrooms from each storage condition each seven days from day 0 to day 28 of storage. Tasters were previously trained for three sessions of $45 \mathrm{~min}$. The analyses were conducted according to the ISO 11035:1994 and the following sensory parameters were assessed: external aspect, hymenium appearance, texture, aroma, taste and general acceptability. Each parameter was assessed with a nine-point rating scale. The values presented for each sampling day and batch are the average of three measurements (one per tray, three trays per sampling day and batch). The end of shiitake shelf life was established when the score of either of the attributes dropped below 6.0.

\subsection{Strains Isolation and Identification}

The PCA agar plates of the microbiological analysis were used for strain isolation and identification. For each combination of sampling day and batch, we picked six colonies on the basis of their morphology and relative frequency, using a stereomicroscope Leica EZ4 (Wetzlar, Germany). Then, culture plates were incubated for five days-longer than in the counting protocol-to more easily detect morphology differences. DNA isolation was performed following Barghouthi (2011) [9] and using PrepMan ${ }^{\circledR}$ Ultra Sample Preparation Reagent (Applied Biosystems, Foster City, CA, USA) as extract agent. Universal primers employed for amplifying V1-V9 region of the $16 \mathrm{~S} r R N A$ gene sequence were: 8F (5'-AGAGTTTGATCCTGGCTCAG-3') and 1492R (5'- CGGTTACCTTGTTACGACTT-3'). The amplification reaction was prepared for a $25 \mu \mathrm{L}$ final volume, containing: $12 \mu \mathrm{L}$ of sterile double distilled water, $1 \mu \mathrm{L}$ of each primer, $1 \mu \mathrm{L}$ of BSA (bovine serum albumin), $2.5 \mu \mathrm{L}$ of Taq free DNA polymerase (Invitrogen, Carlsbad, CA, USA), $5 \mu \mathrm{L}$ of PCR reaction buffer including dNTP and $\mathrm{MgCl}_{2}$ (Invitrogen), and $2.5 \mu \mathrm{L}$ of template DNA. PCR was performed on MyCycler Thermal Cycler (Bio-Rad, Hercules, CA, USA). The following amplification program was used: $94{ }^{\circ} \mathrm{C}$ for $2 \mathrm{~min}, 30$ cycles of $94{ }^{\circ} \mathrm{C} 30 \mathrm{~s}, 51^{\circ} \mathrm{C} 60 \mathrm{~s}, 72{ }^{\circ} \mathrm{C} 1 \mathrm{~min}$, and $7 \mathrm{~min}$ at $72{ }^{\circ} \mathrm{C}$. Samples were kept at $4{ }^{\circ} \mathrm{C}$ until revealing by electrophoresis. $1.5 \%$ agarose gel was performed with $30 \mathrm{~mL}$ of TAE buffer (Buffer Tris, Acetic Acid, EDTA) and $0.8 \mu \mathrm{L}$ of Midori Green (NIPPON Genetics GmbH, Düren, Germany); $60 \mathrm{mV}$ of current was used from an electrophoresis source BioRad PowerPac HV (BioRad, Hercules, CA, USA). 
Band revelation was carried out in a transilluminator (Chemidoc XRS + BioRad, USA) with GeneSys software (Syngene, Cambridge, UK). Amplicons were sequenced by an external company (STAB VIDA, Caprica, Portugal). Sequences were then checked for quality using 4Peaks (Nuclebytes, Amsterdam, The Netherlands) and identified by highest similarity using BLAST algorithm in Genbank.

\subsection{Pathogenicity Test}

The strains isolated for identification (Table 3) were revivified in Tryptone Soy Broth (TSB) (Sigma Aldrich, Saint Louis, MO, USA). After $24 \mathrm{~h}$ of incubation at $30^{\circ} \mathrm{C}, 200 \mu \mathrm{L}$ of each isolated strain was inoculated on slices of L. edodes and $70 \mu \mathrm{L}$ on mushroom caps of L. edodes. Before the inoculation, the concentration was measured and adjusted to $10^{8} \mathrm{cfu} / \mathrm{mL}$ according to McFarland scale. For comparison purposes, cultivated A. bisporus slices were also included in this test. Mushroom slices were placed in Petri dishes and mushroom caps in plastic trays covered with film to prevent dehydration. Both containers were incubated at $10{ }^{\circ} \mathrm{C}$ for two weeks, until damages around the inoculation spots were general. Distilled water was used as a negative control. Biodeterioration was evaluated using a four-level rating scale: 0 -no damage; 1 -damage in the inoculation area; 2-widespread damage in the inoculation area; 3-severe damage to the carpophore (Supplementary Materials Figure S1).

\subsection{Antibiogram Assay}

Mycelial shiitake agar disks of $4 \mathrm{~mm}$ of diameter were removed using a sterile cork borer, aseptically transferred into PDA agar (Merk) and incubated for $24 \mathrm{~h}$ at $25^{\circ} \mathrm{C}$. Then, the bacterial strains (the same ones used for the pathogenicity test) were inoculated with a sterile loop, approximately $2.5 \mathrm{~cm}$ away from shiitake mycelium, and further incubated for 2 weeks at $25^{\circ} \mathrm{C}$. Sterile distilled water was used as a negative control. Three inoculations per strain were prepared. The effect was visually evaluated.

\subsection{Statistical Analysis}

Data were analysed through the $t$-student test and one-way analysis of variance (ANOVA) using SPSS (Windows 2006; Statistical Analysis). It was checked that the models met the assumptions of normal distribution and constant variance. The different treatments and sampling times were compared using post-hoc Tukey's test with a significance level of $p<0.05$. The pathogenicity test was analysed through ordinal logistic regression.

\section{Results and Discussion}

\subsection{Modification of Package Atmosphere Composition}

During the first $48 \mathrm{~h}$, the $\mathrm{CO}_{2}$ and $\mathrm{O}_{2}$ gas concentrations reached values of $10 \%$. The equilibrium was reached after two weeks, with $\mathrm{CO}_{2}$ and $\mathrm{O}_{2}$ concentrations of $16 \%$ and $7 \%$, respectively (Figure 1 ). An excessive accumulation of $\mathrm{CO}_{2}$ could cause physiological lesions to fungi, producing severe browning, or stimulating the proliferation of facultative anaerobic microorganisms. The lack of oxygen could lead to an anoxia situation, accompanied by strange odours due to the production of volatile substances such as ethanol and acetaldehyde [10]. Shiitake has a higher respiratory rate and a greater susceptibility to elevated concentrations of $\mathrm{CO}_{2}$ than other fungal species [2]. In this respect, previous studies compared MAP packaging with low-density polyethylene (PE) and polypropylene (PP) films [2]. In both cases, $\mathrm{O}_{2}$ concentration decreased and $\mathrm{CO}_{2}$ increased rapidly during the first days of storage. However, after that, the $\mathrm{CO}_{2}$ concentration remained constant at very different levels, $13.6 \%$ for PP and $9 \%$ for PE. Our results show similar dynamics to those previously obtained with PP films, although with slightly higher levels of $\mathrm{CO}_{2}$, likely because of the plastic film characteristics (permeability, size and number of perforations), or of the intra-specific differences among L. edodes 
strains, as other authors reported [2]. Moreover, our results agree with those obtained for hypogeous mushrooms when using similar storage conditions $[4,6]$.

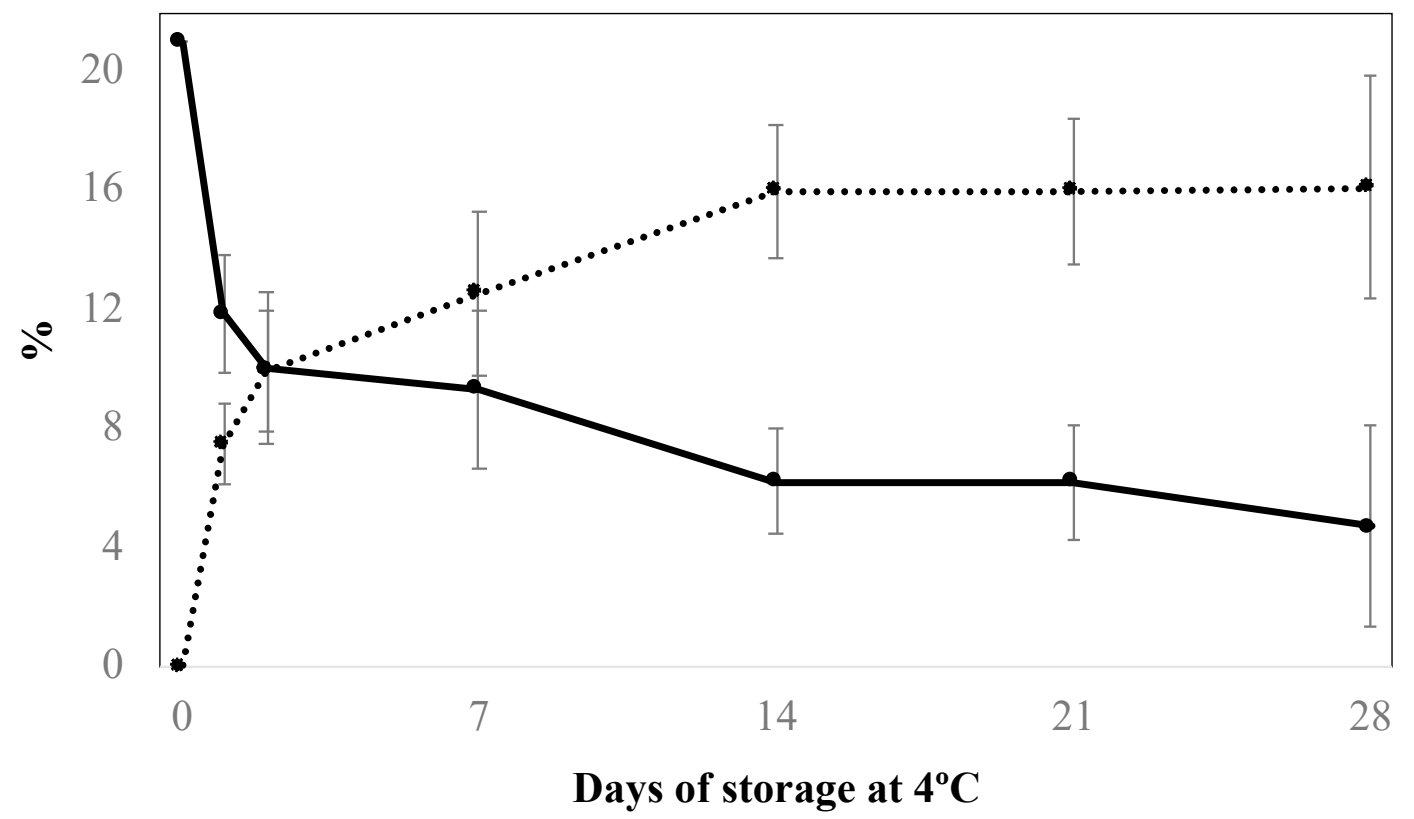

Figure 1. Time trend of $\mathrm{CO}_{2}\left(\cdots \cdots\right.$ dashed line) and $\mathrm{O}_{2}(\rightarrow-$ continuous line) of shiitake mushrooms packaged under modified atmosphere stored at $4{ }^{\circ} \mathrm{C}$. Data expressed as mean \pm standard deviation (SD) of three samples.

\subsection{Time Trend of Weight}

The control batch suffered a weight loss of almost $80 \%$ after one week of storage (Table 1 ). This was probably caused by a quick dehydration related to the respiratory activity of L. edodes carpophores, which is very high at room temperature $[4,6]$. Weight loss was reduced to $25 \%$ when refrigeration was applied (Table 1). By incorporating MAP packaging, the weight only dropped by $2 \%$ during the first week (Table 1). At the end of the storage time, the R batch lost over $80 \%$ of the initial weight, whereas in the MAP batch the weight loss did not exceed 5\% (Table 1). Previous studies also obtained lower weight losses with microperforated than with macroperforated films ( $5 \%$ and $47 \%$, respectively, after 16 days of storage under refrigeration) [2].

Table 1. Weight loss (\%) in L. edodes under different storage conditions: room temperature (C), refrigerated at $4{ }^{\circ} \mathrm{C}(\mathrm{R})$, and modified atmosphere packaging at $4{ }^{\circ} \mathrm{C}(\mathrm{MAP})$. Data expressed as mean \pm standard deviation $(\mathrm{SD})$ of three samples. Different letters within the same column indicate statistically significant differences at $p<0.05$.

\begin{tabular}{cccc}
\hline Day & $\mathbf{C}$ & $\mathbf{R}$ & MAP \\
\hline 0 & $0.0 \pm 0.0^{\mathrm{b}}$ & $0.0^{\mathrm{a}} \pm 0.0^{\mathrm{d}}$ & $0.0 \pm 0.0^{\mathrm{c}}$ \\
7 & $78.1 \pm 5.9^{\mathrm{a}}$ & $24.7 \pm 4.6^{\mathrm{c}}$ & $2.3 \pm 0.6^{\mathrm{b}}$ \\
14 & - & $36.4 \pm 4.0^{\mathrm{bc}}$ & $2.5 \pm 0.4^{\mathrm{b}}$ \\
21 & - & $50.5 \pm 5.1^{\mathrm{b}}$ & $3.0 \pm 0.1^{\mathrm{b}}$ \\
28 & - & $84.2 \pm 5.7^{\mathrm{a}}$ & $4.9 \pm 0.7^{\mathrm{a}}$ \\
\hline
\end{tabular}

\subsection{Time Trend of Microbial Populations}

Initial total AMM load was $5 \log \mathrm{cfu} / \mathrm{g}$. Genus Pseudomonas was the most frequently isolated group ( $4.7 \log \mathrm{cfu} / \mathrm{g})$, followed by moulds and yeasts $(4.1 \log \mathrm{cfu} / \mathrm{g}$ ) and Enterobacteriaceae family ( $3.5 \mathrm{log} \mathrm{cfu} / \mathrm{g})$. Lactic acid bacteria showed much lower values (2.5 log cfu/g) (Figure 2). Venturini et al. obtained 
similar microbial loads for shiitake [11], whereas Jiang et al. showed lower counts for AMM than for Pseudomonas [12]. In comparison with other mushroom species, the microbial load of L. edodes is lower than those reported in A. bisporus (7.5 and $7.2 \log$ cfu/g of AMM and Pseudomonas, respectively), possibly due to the antimicrobial potential of this species [11].
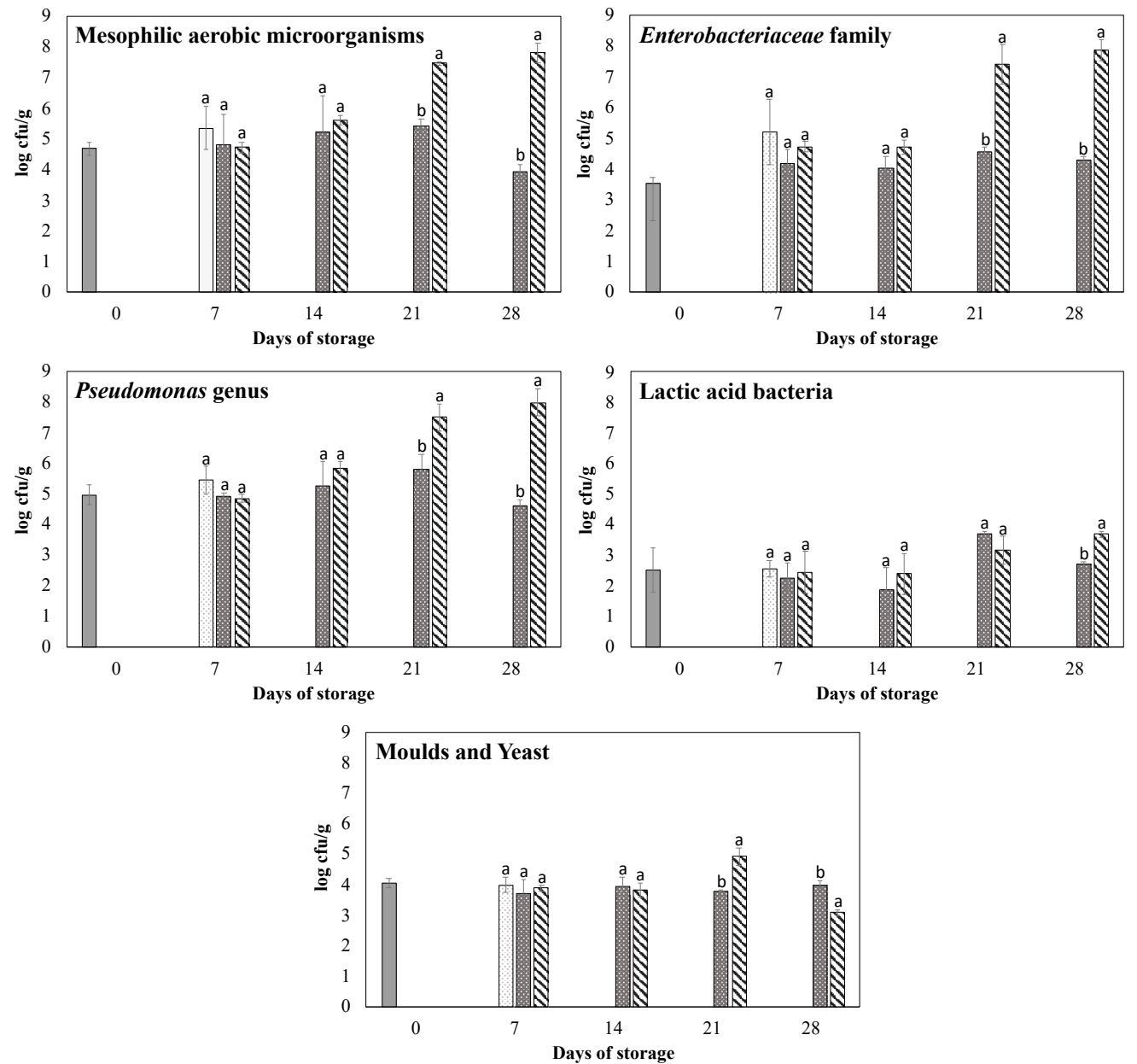

Figure 2. Time trend of mesophilic aerobic microorganisms, Pseudomonas genus, Enterobacteriaceae family, lactic acid bacteria and yeasts populations for fresh L. edodes stored under different conditions: $\square$ initial counts, $\square$ room temperature, 8 refrigerated at $4{ }^{\circ} \mathrm{C}$, and $\mathbf{\nabla}$ modified atmosphere packaging at $4{ }^{\circ} \mathrm{C}$. Data expressed as mean \pm standard deviation (SD) of three samples. ${ }^{\mathrm{a}, \mathrm{b}}$ Different superscript letters within the same day of storage indicate statistically significant differences at $p<0.05$.

The microbial load increased slightly during storage for all groups, although there were no significant differences until the third week (Figure 2). The $C$ batch was unacceptable after one week due to the great loss of moisture and the resulting changes in organoleptic characteristics (see below). On day 28 of storage, the R batch suffered a slight decrease in AMM, Pseudomonas, and LAB contents of almost $1 \mathrm{u} . \log$, which was likely related to dehydration. In contrast, the MAP treatment increased all microbial groups counts on day 28, except for moulds and yeasts. The decrease in moulds count could be explained by the fungicide effect of the high $\mathrm{CO}_{2}$ concentration $(16 \%)$, and in the case of yeasts by the longer generational time than bacteria and the increased nutrient competition exerted by bacteria. The $\mathrm{CO}_{2}$ had no apparent bactericidal effect on Pseudomonas, even though this group is strictly aerobic. This could be explained by the high humidity inside the package (and therefore on the surface of the carpophore) facilitating microbial proliferation. It is remarkable that on day $28 \mathrm{MAP}$ differed to R in more than 3 u.log of AMM, Pseudomonas and Enterobacteriaceae. Finally, although the high levels of $\mathrm{CO}_{2}$ facilitated LAB growth, there were no significant differences among batches until day 28 of storage. 
Jiang et al. applied MAP to shiitake, and reported similar counts of AMM (7.3 log cfu/g), and higher counts of Pseudomonas (8.7 log cfu/g), and moulds and yeasts ( $6.8 \mathrm{log} \mathrm{cfu} / \mathrm{g}$ ) after 20 days of conservation [12]. The MAP of the hypogeous fungi Tuber melanosporum Vittad. and Tuber aestivum Vittad. at $4{ }^{\circ} \mathrm{C}$ barely increased AMM load by 2 u.log after four weeks of storage [6]. This difference might be related to the lower initial microbial load of shiitake, 2 log cfu/g lower than those found in Tuber genus, and by the greater availability of nutrients on shiitake surface. These factors could explain that shiitake microbial populations have higher possibilities of proliferation under propitious conditions of high humidity.

\subsection{Sensory Evaluation and Shelf Life}

Externally, the deterioration of shiitake mushrooms was characterised by the presence of superficial white spots, dehydration and darkening of the carpophores. After one week, the $\mathrm{C}$ batch showed lower values than $\mathrm{R}$ and MAP for all the sensory parameters tested (Table 2). In the $\mathrm{C}$ batch, the shelf life was established in less than one week, due to moisture loss and subsequent changes in external and hymenium appearance, with values of 5.8 and 4.7 on day 7 , respectively (Table 2). In the $\mathrm{R}$ and MAP batches, the shelf life increased by two weeks. The $\mathrm{R}$ batch was considered unacceptable on day 21 due to texture changes, value of 5.5, whereas the MAP batch was rejected due to the darkening of the carpophores and taste changes, with values of 5.5 and 4.7, respectively, and the increase of the microbial load (i.e., the visualisation of superficial microbial growth) (Table 2). The use of MAP prevented moisture losses; however, this allowed the microbial proliferation on the mushroom surface during storage. Thus, MAP did not seem to contribute to increase the shelf life, although it significantly reduced dehydration and preserved texture. The observations on day 28 confirmed those of previous samplings.

Table 2. Time trend of the sensory parameters of L. edodes under different storage conditions: room temperature $(\mathrm{C})$, refrigerated at $4{ }^{\circ} \mathrm{C}(\mathrm{R})$, and modified atmosphere packaging at $4{ }^{\circ} \mathrm{C}(\mathrm{MAP})$. Each of the sensory attributes was scored on a $1-9$ scale $(1=$ definitely unacceptable, $3=$ unacceptable, $5=$ may be acceptable, $7=$ acceptable, and $9=$ definitely acceptable). Data expressed as mean \pm standard deviation (SD) of three samples.

\begin{tabular}{|c|c|c|c|c|c|c|c|}
\hline Day & $\begin{array}{l}\text { Storage } \\
\text { Condition }\end{array}$ & $\begin{array}{c}\text { External } \\
\text { Appearance }\end{array}$ & $\begin{array}{l}\text { Hymenium } \\
\text { Appearance }\end{array}$ & Texture & Aroma & Taste & $\begin{array}{c}\text { General } \\
\text { Acceptability }\end{array}$ \\
\hline \multirow{3}{*}{0} & $\mathrm{C}$ & $9.0 \pm 0.0^{\mathrm{a}}$ & $9.0 \pm 0.0^{a}$ & $9.0 \pm 0.0^{a}$ & $9.0 \pm 0.0^{\mathrm{a}}$ & $9.0 \pm 0.0^{a}$ & $9.0 \pm 0.0^{a}$ \\
\hline & $\mathrm{R}$ & $9.0 \pm 0.0^{\mathrm{a}}$ & $9.0 \pm 0.0^{\mathrm{a}}$ & $9.0 \pm 0.0^{\mathrm{a}}$ & $9.0 \pm 0.0^{a}$ & $9.0 \pm 0.0^{\mathrm{a}}$ & $9.0 \pm 0.0^{\mathrm{a}}$ \\
\hline & MAP & $9.0 \pm 0.0^{\mathrm{a}}$ & $9.0 \pm 0.0^{\mathrm{a}}$ & $9.0 \pm 0.0^{\mathrm{a}}$ & $9.0 \pm 0.0^{a}$ & $9.0 \pm 0.0^{\mathrm{a}}$ & $9.0 \pm 0.0^{a}$ \\
\hline \multirow{3}{*}{7} & C & $5.8 \pm 1.5^{b}$ & $4.7 \pm 0.9^{b}$ & $6.5 \pm 0.8^{b}$ & $7.1 \pm 0.5^{b}$ & $6.8 \pm 0.8^{b}$ & $5.8 \pm 1.2^{b}$ \\
\hline & $\mathrm{R}$ & $8.4 \pm 0.5^{\mathrm{a}}$ & $8.2 \pm 0.3^{a}$ & $8.6 \pm 0.2^{a}$ & $8.5 \pm 0.1^{a}$ & $8.5 \pm 0.2^{a}$ & $8.3 \pm 0.5^{\mathrm{a}}$ \\
\hline & MAP & $8.3 \pm 0.7^{\mathrm{a}}$ & $8.6 \pm 0.3^{a}$ & $8.8 \pm 0.1^{a}$ & $8.7 \pm 0.2^{\mathrm{a}}$ & $8.6 \pm 0.3^{a}$ & $8.5 \pm 0.4^{\mathrm{a}}$ \\
\hline \multirow{3}{*}{14} & C & $1.7 \pm 0.9^{b}$ & $1.1 \pm 0.3^{b}$ & $3.0 \pm 0.5^{b}$ & $4.5 \pm 0.5^{b}$ & - & $2.1 \pm 0.5^{b}$ \\
\hline & $\mathrm{R}$ & $7.5 \pm 0.7^{\mathrm{a}}$ & $7.9 \pm 0.5^{\mathrm{a}}$ & $7.2 \pm 0.5^{a}$ & $7.3 \pm 0.4^{\mathrm{a}}$ & $7.7 \pm 0.6^{a}$ & $7.5 \pm 0.4^{\mathrm{a}}$ \\
\hline & MAP & $7.1 \pm 0.9^{a}$ & $7.7 \pm 0.6^{\mathrm{a}}$ & $8.1 \pm 0.4^{\mathrm{a}}$ & $7.9 \pm 0.6^{a}$ & $7.5 \pm 0.7^{\mathrm{a}}$ & $7.0 \pm 0.6^{\mathrm{a}}$ \\
\hline \multirow{3}{*}{21} & C & - & - & - & - & - & - \\
\hline & $\mathrm{R}$ & $7.0 \pm 1.1^{\mathrm{a}}$ & $7.1 \pm 0.8^{a}$ & $5.5 \pm 0.4^{b}$ & $6.6 \pm 0.8^{a}$ & $6.6 \pm 0.8^{a}$ & $6.5 \pm 0.8^{a}$ \\
\hline & MAP & $5.5 \pm 0.7^{\mathrm{a}}$ & $5.8 \pm 0.9^{a}$ & $7.2 \pm 0.8^{a}$ & $5.7 \pm 1.1^{\mathrm{a}}$ & $4.9 \pm 0.3^{b}$ & $5.0 \pm 1.1^{b}$ \\
\hline \multirow{3}{*}{28} & C & - & - & - & - & - & - \\
\hline & $\mathrm{R}$ & $5.4 \pm 0.8^{a}$ & $5.1 \pm 0.3^{a}$ & $3.8 \pm 0.7^{a}$ & $5.9 \pm 0.4^{\mathrm{a}}$ & $6.0 \pm 1.2$ & $5.1 \pm 1.0^{\mathrm{a}}$ \\
\hline & MAP & $1.5 \pm 1.1^{b}$ & $2.1 \pm 0.3^{b}$ & $5.1 \pm 0.4^{a}$ & $3.1 \pm 0.7^{b}$ & - & $1.3 \pm 0.4^{b}$ \\
\hline
\end{tabular}

$\mathrm{a}, \mathrm{b}$ Different letters denote significant differences $(p \leq 0.05)$ between storage treatments for the same day.

\subsection{Identification of Bacterial Isolates}

A total of 48 different strains were selected on the basis of colony morphology in PCA agar. The bacterial sequences were deposited in GenBank under accession numbers from MT335639 to MT335686 (Supplementary Materials Table S1). Almost all the strains isolated throughout the shelf 
life of shiitake were Gram-negative, specifically gamma proteobacteria belonging to the Pseudomonas genus and the Enterobacteriaceae family (Table 3). Within this last group of facultative aero-anaerobic bacteria, E. americana predominated with 18 strains. In addition, 21 different strains of Pseudomonas were found. Some of these bacteria are responsible for the degradation of the carpophores of various fungal species, due to the toxins they produce [13] or to their pathogenic nature [7]. Aslani et al. [14] isolated 18 Gram-negative strains from mushrooms with symptoms similar to those of brown blotch disease, and 66 strains from different species of wild mushrooms, in which $58 \%$ were Gram-negative and 42\% Gram-positive. These authors identified Pseudomonas and Serratia strains, but also Bacillus, Stenotrophomonas and Brochothrix strains.

Table 3. List of the strains isolated during the microbiological analysis, Genbank accession numbers, and results of the biodeterioration evaluation with a pathogenicity test. The genus corresponds to the best BLAST hit in Genbank database for each bacterial strain, as detailed in Table S1. The pathogenicity test was performed on mushroom slices of L. edodes and A. bisporus, and on cap cuticle of L. edodes. The biodeterioration was scored on a 0-3 scale (0: no appreciable damage, 1 : slight damage in the inoculation area, 2: extended damage around the inoculation area, 3: severe damage throughout the carpophore sample). Data are disaggregated by the day of storage in which the strain was retrieved (D0-D28) and by the batch from which the strain was retrieved (C: room temperature; R: refrigerated at $4{ }^{\circ} \mathrm{C}$; MAP: modified atmosphere packaging at $4{ }^{\circ} \mathrm{C}$ ).

\begin{tabular}{|c|c|c|c|c|c|}
\hline \multirow{2}{*}{ Day-Storage } & \multirow{2}{*}{ Accession Number } & \multirow{2}{*}{ Genus } & \multicolumn{2}{|c|}{ L.edodes } & \multirow{2}{*}{$\begin{array}{c}\text { A. bisporus } \\
\text { Slices }\end{array}$} \\
\hline & & & Slices & Cap & \\
\hline D0 & MT335659 & Microbacterium & 3 & 3 & 0 \\
\hline D0 & MT335657 & Paenibacillus & 0 & 2 & 2 \\
\hline D0 & MT335639 & Ewingella & 1 & 1 & 0 \\
\hline D0 & MT335646 & Pseudomonas & 0 & 1 & 1 \\
\hline D0 & MT335652 & Pseudomonas & 0 & 1 & 0 \\
\hline D0 & MT335647 & Pseudomonas & 0 & 1 & 1 \\
\hline D7-C & MT335641 & Ewingella & 0 & 2 & 2 \\
\hline D7-C & MT335650 & Pseudomonas & 1 & 1 & 1 \\
\hline D7-C & MT335667 & Pseudomonas & 3 & 1 & 0 \\
\hline D7-C & MT335653 & Pseudomonas & 3 & 1 & 2 \\
\hline D7-C & MT335673 & Pseudomonas & 0 & 1 & 2 \\
\hline D7-C & MT335654 & Pseudomonas & 3 & 1 & 3 \\
\hline D7-R & MT335642 & Ewingella & 1 & 2 & 3 \\
\hline D7-R & MT335644 & Ewingella & 2 & 1 & 1 \\
\hline D7-R & MT335648 & Ewingella & 3 & 1 & 1 \\
\hline D7-R & МТ335656 & Ewingella & 3 & 1 & 2 \\
\hline D7-R & MT335683 & Pseudomonas & 3 & 1 & 1 \\
\hline D7-R & MT335651 & Pseudomonas & 1 & 0 & 0 \\
\hline D7-MAP & MT335643 & Micrococcus & 0 & 2 & 2 \\
\hline D7-MAP & MT335658 & Ewingella & 3 & 1 & 1 \\
\hline D7-MAP & MT335660 & Ewingella & 0 & 2 & 3 \\
\hline D7-MAP & MT335679 & Pseudomonas & 1 & 1 & 1 \\
\hline D7-MAP & MT335645 & Pseudomonas & 3 & 2 & 1 \\
\hline D7-MAP & MT335661 & Serratia & 3 & 2 & 1 \\
\hline D14-R & MT335662 & Ewingella & 3 & 2 & 1 \\
\hline D14-R & MT335666 & Ewingella & 3 & 3 & 1 \\
\hline D14-R & MT335665 & Ewingella & 3 & 2 & 0 \\
\hline D14-R & MT335684 & Pseudomonas & 1 & 2 & 2 \\
\hline D14-R & MT335664 & Pseudomonas & 3 & 1 & 2 \\
\hline D14-R & МТ335669 & Serratia & 3 & 0 & 2 \\
\hline D14-MAP & MT335649 & Burkholderia & 3 & 2 & 3 \\
\hline D14-MAP & MT335663 & Ewingella & 3 & 2 & 2 \\
\hline D14-MAP & МТ335671 & Ewingella & 3 & 1 & 3 \\
\hline D14-MAP & MT335675 & Pseudomonas & 3 & 2 & 2 \\
\hline D14-MAP & MT335640 & Pseudomonas & 3 & 2 & 2 \\
\hline D14-MAP & MT335676 & Pseudomonas & 1 & 2 & 1 \\
\hline
\end{tabular}


Table 3. Cont.

\begin{tabular}{cccccc}
\hline \multirow{2}{*}{ Day-Storage } & \multirow{2}{*}{ Accession Number } & \multirow{2}{*}{ Genus } & \multicolumn{2}{c}{ L.edodes } & A. bisporus \\
\cline { 4 - 6 } & & & Slices & Cap & Slices \\
\hline D28-R & MT335686 & Ewingella & 3 & 1 & 3 \\
D28-R & MT335674 & Ewingella & 3 & 3 & 2 \\
D28-R & MT335680 & Ewingella & 3 & 2 & 3 \\
D28-R & MT335685 & Ewingella & 3 & 2 & 2 \\
D28-R & MT335670 & Pseudomonas & 3 & 2 & 1 \\
D28-R & MT335678 & Pseudomonas & 3 & 1 & 1 \\
D28-MAP & MT335682 & Paenarthrobacter & 1 & 1 & 3 \\
D28-MAP & MT335672 & Ewingella & 3 & 1 & 3 \\
D28-MAP & MT335668 & Ewingella & 3 & 1 & 3 \\
D28-MAP & MT335677 & Pseudomonas & 3 & 1 & 3 \\
D28-MAP & MT335681 & Pseudomonas & 0 & 1 & 2 \\
D28-MAP & MT335655 & Rahnella & 3 & 2 & 3 \\
\hline
\end{tabular}

\subsection{Biodeterioration Capacity of the Isolated Strains}

Almost all the strains of E. americana and Pseudomonas used in the pathogenicity test caused severe damages on shiitake slices (Table 3). Microbacterium sp., Burkholderia sp., Serratia sp. and Rahnella sp. strains also produced severe damages scoring three in damage scale. In contrast, one strain of Pseudomonas and one of Serratia were the only ones that did not apparently damage shiitake caps (score 0). The slices of $A$. bisporus were not damaged by Microbacterium sp., two strains of E. americana and three of Pseudomonas (Table 3).

Among the isolated species, P. tolaasii, E. americana and some species of the Burkholderia genus are usually the cause of different mushroom diseases [5-7]. The reservoir of E. americana is unknown, but it has been isolated as an opportunistic pathogen from carrots [15] and vacuum-packed meat [16]. Ewingella americana has been reported as a mycopathogenic agent causing a brown lesion and necrosis in mushroom stems [7]. Burkholderia gladioli is an important pathogen causing the softening and deterioration of various commercial mushrooms, such as L. edodes, A. bisporus and P. ostreatus [8]. However, as far as we know, this is the first time that Rahnella sp. has been isolated from mushroom carpophores.

The ability of the strains isolated on days 7 to 28 to deteriorate L. edodes caps was significantly higher than that of the strains isolated on day 0 (z-ratio $=-5.7,-8.7$ and -7.7 , with $p$-value $<0.001$ in all cases) (Figure 3A). The slices of L. edodes were significantly more damaged than its cap cuticle (z-ratio $=-3.6, p$-value $<0.001$ ) (Figure 3B). This clearly indicates that the cuticle serves as a barrier against microbial deterioration [14]. The isolated bacterial strains produced a higher damage level on shiitake slices than on A. bisporus slices (z-ratio $=2.9, p$-value $=0.011$ ) (Figure 3B). This could be due to differences in the enzymatic repertoire of the various bacterial strains or to bacterial strains having higher deterioration ability on the mushroom species from which they are isolated [5,8,14]. Regarding the latter hypothesis, it would be interesting to test whether bacterial strains develop pathogenic mechanisms specific to the mushroom in which they grow. 
A

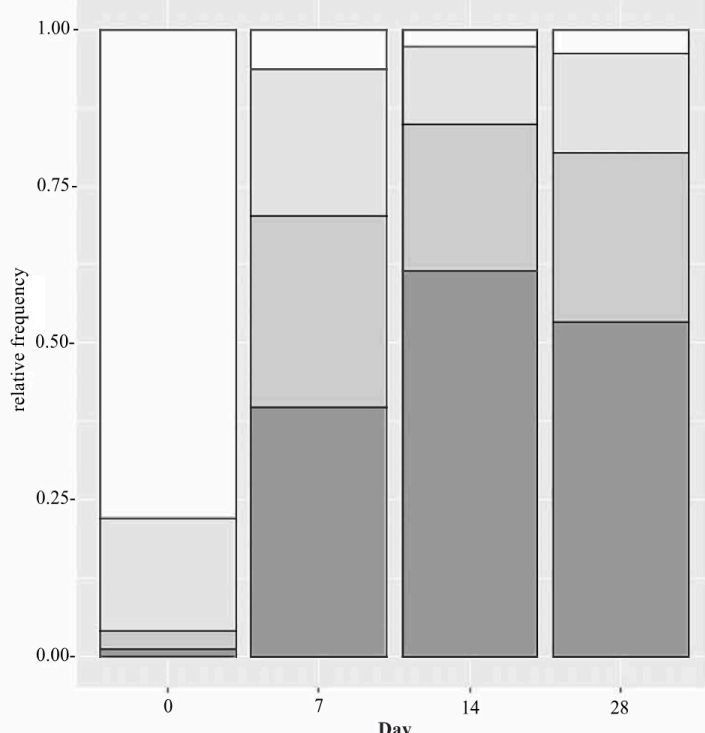

B

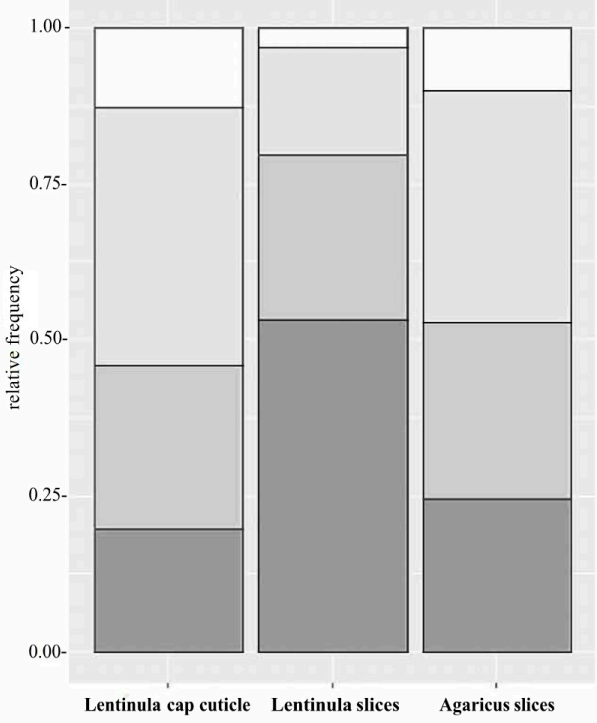

Figure 3. Predicted damage severity caused to L. edodes tissues by the microbial strains inoculated in the pathogenicity test, according to the day of storage in which the strains were isolated (A). Mean damage levels provoked by the inoculated microbial strains (all time points pooled) on L. edodes and A. bisporus tissues (B): $\square$ 0: no appreciable damage, $\square$ 1: slight damage in the inoculation area, $\square$ 2: extended damage in the inoculation area, $\square$ 3: severe damage throughout the carpophore sample.

\subsection{Inhibition of Mycelium Growth}

In the antibiogram test, most of the inoculated strains did not affect mycelial growth, although some strains showed a slight inhibition around the colony, preventing L. edodes mycelium from growing above them. Only Rahnella sp. had a clear effect on the mycelium of shiitake, inhibiting its growth and provoking mycelium browning (Figure 4). Rahnella sp. could be releasing compounds to the media that might be responsible for mushroom browning and mycelium growth inhibition. However, Rao et al. tested an aqueous extract of shiitake against Rahnella, obtaining low levels of inhibition [17]. It is remarkable that we did not find any inhibition effect for any of the tested Pseudomonas strains. This contrasts with previous research describing that $P$. tolaasii produces volatile compounds such as methanethiol, dimethyl disulfide and 1-undecene that inhibit in vitro mycelium growth of several fungi and causes mycelium browning [18].

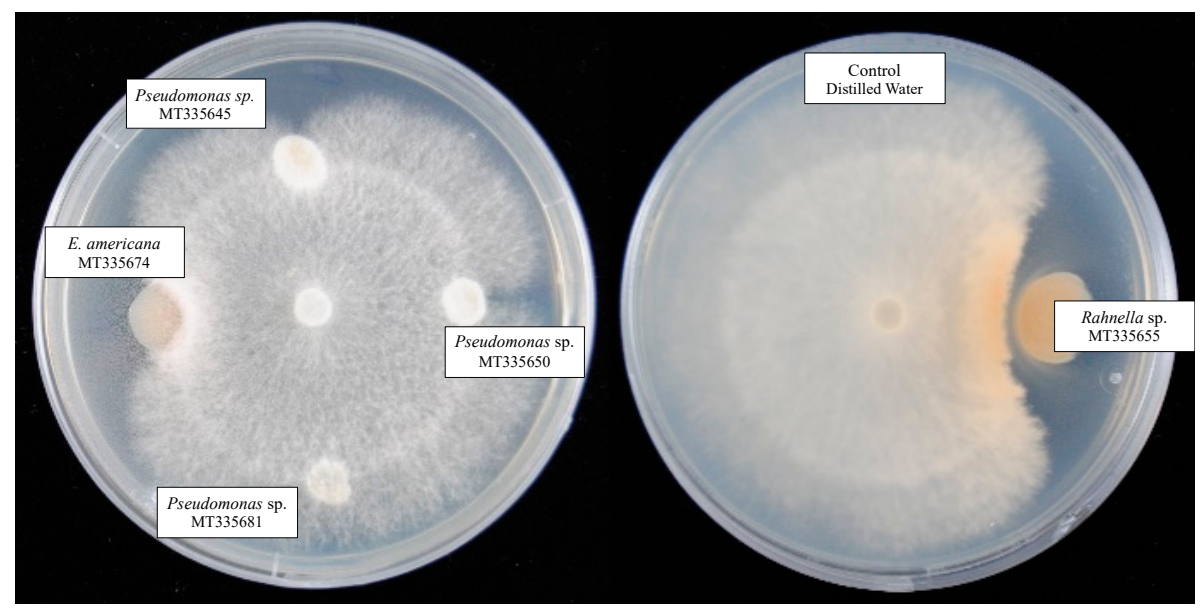

Figure 4. Inhibition of L. edodes mycelium (in the center of the plate) by the isolated strains, and negative control (sterile distilled water). Strains were incubated for two weeks at $10{ }^{\circ} \mathrm{C}$. 


\section{Conclusions}

We found that weight loss, sensory parameters, and the increase of microbial load were the main constraints to shiitake shelf life under different conservation conditions. The application of low temperatures reduced weight loss and extended the shelf life for two weeks. Although MAP was not able to extend the shelf life in comparison to refrigeration, it could be extremely recommendable to prevent weight loss. The microbial analysis of shiitake carpophores showed that Pseudomonas ( $4.7 \log \mathrm{cfu} / \mathrm{g})$ and Enterobacteriaceae ( $3.5 \mathrm{log} \mathrm{cfu} / \mathrm{g}$ ) were the most frequently isolated microbial groups. A total of 48 isolated strains were identified. Among them, E. americana, Burkholderia sp., Serratia sp., Rahnella sp. and some Pseudomonas strains were able to damage shiitake carpophores. Only Rahnella sp. showed an inhibitory effect on shiitake mycelium growth. The study demonstrated the major role of Gram-negative bacteria on L. edodes deterioration. Furthermore, the biodeterioration capacity of the isolated strains increased throughout the conservation period, with cap slices being more affected than the cap cuticle, and with bacterial strains isolated from L. edodes showing higher damaging ability on the mushroom species from which they were isolated than on A. bisporus.

Supplementary Materials: The following are available online at http://www.mdpi.com/2073-4395/10/6/898/s1, Figure S1: Levels of damage severity on L. edodes tissues by the microbial strains inoculated in the pathogenicity test analysed on experimental day seven; Table S1: Genbank Accession Numbers of Bacterial strains isolated from shiitake mushroom (Lentinula edodes) in this work and best BLAST hit sequences used for identifications.

Author Contributions: Methodology, P.M. and S.S.; Formal Analysis, E.T.-C. and P.M.; Investigation, E.T.-C.; Data Curation, S.G.-B.; Writing, all authors; Review and Editing, P.M. All authors have read and agreed to the published version of the manuscript.

Funding: This research was funded by INIA grant number RTA2015-00053-00-00.

Conflicts of Interest: The authors declare no conflict of interest.

\section{References}

1. Gil-Ramírez, A.; Soler-Rivas, C. The use of edible mushroom extracts as bioactive ingredients to design novel functional foods with hypocholesterolemic activities. In Mushrooms: Cultivation, Antioxidant Properties and Health Benefits.; Pesti, G., Ed.; Nova Publishers, Inc.: Hauppauge, NY, USA, 2014; pp. 44-73, ISBN 978-1-63117-521-3.

2. Ares, G.; Parentelli, C.; Gámbaro, A.; Lareo, C.; Lema, P. Sensory shelf life of shiitake mushrooms stored under passive modified atmosphere. Postharvest Biol. Technol. 2006, 41, 191-197. [CrossRef]

3. Han Lyn, F.; Maryam Adilah, Z.A.; Nor-Khaizura, M.A.R.; Jamilah, B.; Nur Hanani, Z.A. Application of modified atmosphere and active packaging for oyster mushroom (Pleurotus ostreatus). Food Packag. Shelf Life 2020, 23, 100451. [CrossRef]

4. Rivera, C.S.; Blanco, D.; Marco, P.; Oria, R.; Venturini, M.E. Effects of electron-beam irradiation on the shelf life, microbial populations and sensory characteristics of summer truffles (Tuber aestivum) packaged under modified atmospheres. Food Microbiol. 2011, 28, 141-148. [CrossRef] [PubMed]

5. Li, J.; Wei, Q.; Huang, L.; Fang, T.; Chen, B.; Jiang, Y. Mathematical modeling Pseudomonas spp. growth and microflora composition variation in Agaricus bisporus fruiting bodies during chilled storage. Postharvest Biol. Technol. 2020, 163, 111144. [CrossRef]

6. Rivera, C.S.; Venturini, M.E.; Marco, P.; Oria, R.; Blanco, D. Effects of electron-beam and gamma irradiation treatments on the microbial populations, respiratory activity and sensory characteristics of Tuber melanosporum truffles packaged under modified atmospheres. Food Microbiol. 2011, 28, 1252-1260. [CrossRef] [PubMed]

7. Reyes, J.E.; Venturini, M.E.; Oria, R.; Blanco, D. Prevalence of Ewingella americana in retail fresh cultivated mushrooms (Agaricus bisporus, Lentinula edodes and Pleurotus ostreatus) in Zaragoza (Spain). FEMS Microbiol. Ecol. 2004, 47, 291-296. [CrossRef]

8. Chowdhury, P.R.; Heinemann, J.A. The general secretory pathway of Burkholderia gladioli pv. agaricicola BG164R is necessary for cavity disease in white button mushrooms. Appl. Environ. Microbiol. 2006, 60, 71-77. [CrossRef] [PubMed] 
9. Barghouthi, S.A. A Universal Method for the Identification of Bacteria Based on General PCR Primers. Indian J. Microbiol. 2011, 51, 430-444. [CrossRef] [PubMed]

10. Combet, E.; Eastwood, D.C.; Burton, K.S.; Combet, E.; Henderson, J.; Henderson, J.; Combet, E. Eight-carbon volatiles in mushrooms and fungi: Properties, analysis, and biosynthesis. Mycoscience 2006, 47, 317-326. [CrossRef]

11. Venturini, M.E.; Rivera, C.S.; Gonzalez, C.; Blanco, D. Antimicrobial activity of extracts of edible wild and cultivated mushrooms against foodborne bacterial strains. J. Food Prot. 2008, 71, 1701-1706. [CrossRef] [PubMed]

12. Jiang, T.; Luo, S.; Chen, Q.; Shen, L.; Ying, T. Effect of integrated application of gamma irradiation and modified atmosphere packaging on physicochemical and microbiological properties of shiitake mushroom (Lentinus edodes). Food Chem. 2010, 122, 761-767. [CrossRef]

13. Soler-Rivas, C.; Jolivet, S.; Arpin, N.; Olivier, J.M.; Wichers, H.J. Biochemical and physiological aspects of brown blotch disease of Agaricus bisporus. FEMS Microbiol. Rev. 1999, 23, 591-614. [CrossRef] [PubMed]

14. Aslani, M.A.; Harighi, B.; Abdollahzadeh, J. Screening of endofungal bacteria isolated from wild growing mushrooms as potential biological control agents against brown blotch and internal stipe necrosis diseases of Agaricus bisporus. Biol. Control 2018, 119, 20-26. [CrossRef]

15. Hamilton-Miller, J.M.; Shah, S. Identity and antibiotic susceptibility of enterobacterial flora of salad vegetables. Int. J. Antimicrob. Agents 2001, 18, 81-83. [CrossRef]

16. Helps, C.R.; Harbour, D.A.; Corry, J.E. PCR-based 16 S ribosomal DNA detection technique for Clostridium estertheticum causing spoilage in vacuum-packed chill-stored beef. Int. J. Food Microbiol. 1999, 52, 57-65. [CrossRef]

17. Rao, J.R.; Millar, B.C.; Moore, J.E. Antimicrobial properties of shiitake mushrooms (Lentinula edodes). Int. J. Antimicrob. Agents 2009, 33, 591-592. [CrossRef] [PubMed]

18. Lo Cantore, P.; Giorgio, A.; Iacobellis, N.S. Bioactivity of volatile organic compounds produced by Pseudomonas tolaasii. Front. Microbiol. 2015, 6, 1082. [CrossRef] [PubMed] 